\title{
Review article \\ Plant-produced viral bovine vaccines: what happened during the last 10 years?
}

\author{
Vanesa Ruiz ${ }^{1,2}$, Marina V. Mozgovoj ${ }^{1,2}$, María José Dus Santos ${ }^{1,2}$ and Andrés Wigdorovitz ${ }^{1,2, *}$ \\ ${ }^{1}$ Instituto de Virología, CICVyA, INTA, Hurlingham, Buenos Aires, Argentina \\ ${ }^{2}$ Consejo Nacional de Investigaciones Científicas y Tecnológicas (CONICET), Ciudad Autónoma de Buenos Aires, Argentina
}

Received 31 March 2015;

revised 5 June 2015;

accepted 27 June 2015.

*Correspondence (Tel (+54 11) 4621 1447;

fax (+54 11) 4621 1743; emails wigdorovitz.

andres@inta.gob.ar; awigdo@gmail.com)

Keywords: vaccines, plant, bovine, virus, virus-like particles, molecular farming.

\begin{abstract}
Summary
Vaccination has proved to be an efficient strategy to deal with viral infections in both human and animal species. However, protection of cattle against viral infections is still a major concern in veterinary science. During the last two decades, the development of efficient plant-based expression strategies for recombinant proteins prompted the application of this methodology for veterinary vaccine purposes. The main goals of viral bovine vaccines are to improve the health and welfare of cattle and increase the production of livestock, in a cost-effective manner. This review explores some of the more prominent recent advances in plant-made viral bovine vaccines against foot-and-mouth disease virus (FMDV), bovine rotavirus (BRV), bovine viral diarrhoea virus (BVDV), bluetongue virus (BTV) and bovine papillomavirus (BPV), some of which are considered to be the most important viral causative agents of economic loss in cattle production.
\end{abstract}

\section{Introduction}

There are more than 1 billion head of cattle in the world (U.S. Department of Agriculture (USDA) (http://www.fas.usda.gov/data/livestock-and-poultry-world-markets-and-trade). The main livestock producers worldwide are India, Brazil and China (with populations ranging from 100 to approximately 300 million heads; followed by the United States, the European Union and Argentina (Figure 1).

Animal health and animal welfare are the main factors to guarantee the safety of food of animal origin. Disease outbreaks can have a devastating effect on animal health, thus affecting animal production and even human health. Vaccination is used primarily to prevent such outbreaks, and vaccines directed against highly contagious viral diseases play a particularly important role as they prevent viral infections which predispose animals to superinfection with bacterial or other opportunistic pathogens.

Nowadays, different veterinary vaccines are available against respiratory and gastrointestinal pathogens, as well as for viruses associated with infertility, malformation, stillbirth or abortion, in cattle (Brun et al., 2011; Crisci et al., 2012; Meeusen et al., 2007). The major goals of viral bovine veterinary vaccine production are to improve the health and welfare of cattle and increase production of livestock, in a cost-effective manner.

For many viral infections of livestock, conventional vaccines cannot be used, as their use would interfere with disease surveillance based on serological testing and may result in the loss of a country's disease-free status. This is the case of the inactivated vaccine against foot-and-mouth disease (FMD) that though quite effective in controlling clinical disease (Doel, 2003) is not used in FMD-free countries as this would compromise their status and hence international trade. In these cases, the use of subunit vaccines combined with suitable diagnostic assays allows differentiating infected from vaccinated animals (DIVA) by differ- entiation of antibody responses induced by the vaccine from those induced during infection with the wild-type virus.

Over the years, several expression systems have been explored for recombinant vaccine production. Each has its own advantages and disadvantages. An ideal expression system must produce the desired, functional product, allow for convenient storage and distribution of the product, be cost-effective, easy to purify, not be time-consuming and should not be associated with the development and release of genetically modified organisms used for production. Conventional expression systems include bacteria, yeast and animal cell culture. During the last few years, insect cells and plants have become alternative platforms to produce recombinant proteins (Brun et al., 2011; Xu et al., 2012).

Plants offer several features that have made them a complementary and attractive strategy. They can successfully perform the majority of post-translational modifications, and they offer increased scalability and production safety, as well as reduced manufacturing costs and regulatory issues. However, this technology still has some shortcomings, mainly associated with low expression levels of the recombinant proteins, the considerably large amount of time and work invested in the production of transgenic plants and the difficulty in the downstream processing of extraction and purification of the product from plant materials. Fortunately, alternatives have been developed to overcome these shortcomings. For example, the first two problems could be solved by performing chloroplast transformation or by transient transformation using virus-derived vectors. The third drawback could be overcome using plant cell culture, although in this case production costs would be increased.

The development of plant-made veterinary vaccines (PMVs) has been frequently reported during the last 20 years (reviewed in Obembe et al., 2011; Rybicki, 2014; Sharma and Sharma, 2009; Yusibov et al., 2011). Foot-and-mouth disease virus (FMDV), bovine rotavirus (BRV) and bovine viral diarrhoea virus (BVDV) are considered to be the most important viral agents causative of economic 

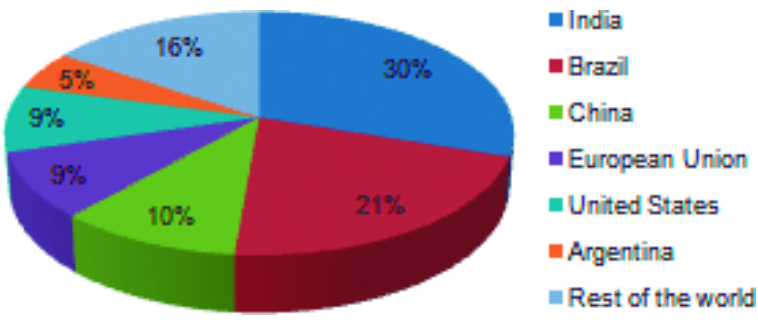

Figure 1 Cattle production by country. Font: USDA (http:// www.fas.usda.gov/data/livestock-and-poultry-world-markets-and-trade).

losses in cattle production, thus emphasizing the demand for alternative means of immunization against them. These viruses, as well as others such as bluetongue virus (BTV) and bovine papillomavirus (BPV), are the ones involved in the development of new generation PMVVs. This review explores some of the most prominent recent advances in plant-made viral bovine vaccines against these viruses and discusses possible future applications.

\section{Foot-and-mouth disease virus}

Foot-and-mouth disease is a highly contagious and devastating viral disease that affects cloven-hoofed animals, including cattle, pigs, buffaloes, sheep, goats and deer. The disease is characterized by fever, loss of appetite, depression, lameness and the appearance of vesicles and erosions in the mouth, nose, teats and feet. Although mortality is generally low in adult animals, the disease has debilitating effects, including weight loss, decrease in milk production and loss of draught power, resulting in serious production losses and a major constraint to international trade in livestock and animal products. For these reasons, it is essential to prevent, control and even eradicate FMD.

The disease is caused by infection with FMD virus (FMDV), a member of the Aphthovirus genus of the Picornaviridae family, which exists in seven antigenically diverse serotypes $(O, A, C$, Asia 1, SAT 1, SAT 2 and SAT 3) with significant strain differences and subtypes within each serotype (Knowles and Samuel, 2003). Although the FMD situation has improved markedly in recent years, the disease remains endemic and at a high prevalence in many countries of Asia, Africa, Middle East and South America (Jamal and Belsham, 2013).

Immunization with the current inactivated FMDV preparations has been successfully used in many parts of the world. However, the requirement for field strain tissue culture adaptation and large volumes of live virus production poses significant biocontainment and biosafety challenges (Rodriguez and Grubman, 2009). Therefore, the development of subunit vaccines based on FMDV capsid proteins, peptides and epitopes has been investigated over the past years, using different expression systems, including several attempts to develop plant-expressed anti-FMDV vaccines (summarized in Table 1).

Many plant viruses have been used successfully for either peptide display or expression of whole antigens on their surface. Chimeric Bamboo mosaic virus (BaMV) expressing $T$ and $B$ epitopes of the FMDV capsid protein VP1 proved to induce not only humoral (as indicated by neutralizing antibodies) and cellmediated immune responses (as indicated by VP1-specific IFN- $\gamma$ production), but also full protection against FMDV in swine (Yang et al., 2007). Similarly, Tobacco necrosis virus-A (TNV-A) was engineered as a vector to express different peptides from FMDV serotype O VP1. Most of the obtained chimaeras contained unmodified foreign peptides even after six successive passages in Chenopodium amaranticolor and three passages in Nicotiana benthamiana. In this study, purified chimaeric virus particles (CVPs) induced a strong immune response in mice after intramuscular immunization and systemic and mucosal immune responses via the intranasal route (Zhang et al., 2010).

Wang et al. (2008) reported the development of an oral immunization system for FMD with the structural protein VP1 produced in transgenic Stylosanthes guianensis cv. Reyan Ipp. Six transformed lines were obtained, and the expression level of the recombinant VP1 protein was $0.1-0.5 \%$ total soluble protein (TSP). These transgenic plants expressing the antigen protein of FMDV serotype O1C as feedstuff additives have demonstrated the induction of a protective systemic antibody response in mice. In another approach, transgenic rice expressing the capsid precursor polypeptide (P1) of FMDV was generated by Agrobacterium-mediated transformation. The level of recombinant protein ranged from 0.6 to $1.3 \mathrm{mg} / \mathrm{g}$ of TSP in transgenic rice leaves, which was demonstrated as being sufficient to induce a protective immune response in mice after intraperitoneal immunization (Wang et al., 2012). In addition, when mice were orally vaccinated, FMDV-specific mucosal immune responses were detected, as well as partial virus clearance after challenge. It is worth noting that the mouse model has been used extensively to study FMDV infection and has successfully predicted immune responses to FMDV in cattle and pigs (Habiela et al., 2014).

The development of transgenic plant edible vaccines has the limitation of the low level of antigen accumulation. To overcome this problem, the recombinant protein can be produced in a subcellular organelle, such as chloroplasts. In this regard, Li et al. (2006) expressed the VP1 protein by tobacco chloroplast transformation reaching values of $2 \%-3 \%$ of TSP. Similarly, our group reported the use of tobacco transplastomic plants to produce a highly immunogenic epitope of VP1 fused to the BGUS protein. In this case, the recombinant protein represented $51 \%$ of the soluble proteins in mature leaves (Lentz et al., 2010) and proved to be immunogenic in mice. The fusion to a highly stable protein (BGUS) could increase the accumulation of the peptide in the chloroplast.

Another approach to produce anti-FMDV vaccines in plants was the expression of a recombinant protein formed by a set of effective epitopes of the virus within a single polypeptide chain. Andrianova et al. (2011) created a recombinant anti-FMD vaccine based on a polyepitope protein, consisting of B-cell epitopes of structural proteins VP1 and VP4 and T-cell epitopes of nonstructural proteins $2 \mathrm{C}$ and 3D. The epitopes were divided by 'flexible' glycine-rich linkers G4S2 to avoid potential problems of protein folding, and the recombinant protein was produced in $N$. benthamiana plants using a phytovirus expression system. A single intramuscular immunization of guinea pigs by emulsion vaccine containing $120 \mu \mathrm{g}$ of the purified protein, induced the formation of virus-neutralizing antibodies to FMD virus type O/Taiwan/99 revealed by indirect ELISA, and it caused resistance to the control infection with the homologous virus. More recently, Rao et al. (2012) reported the development of a bivalent vaccine with tandem-linked VP1 proteins of two serotypes, A and O, present in a transgenic forage crop Crotalaria juncea. The authors tested this bivalent FMD vaccine in guinea pigs, which were immunized with leaf-extracted proteins or oral fed with leaves of the transgenic plants. Guinea pigs reacted to orally or parenterally applied vaccine, by humoral as well as cell-mediated immune responses, that is serum antibodies and stimulated lymphocytes, respectively. Two of three animals (66\%) were protected against a challenge 
Table 1 Development of plant-based vaccines against viral diseases in cattle

\begin{tabular}{|c|c|c|c|c|c|c|}
\hline \multirow[b]{2}{*}{ Animal virus } & \multirow[b]{2}{*}{ Target genes } & \multirow[b]{2}{*}{ Plant/expression system } & \multicolumn{2}{|l|}{ Yield } & \multirow[b]{2}{*}{ Animal model } & \multirow[b]{2}{*}{ References } \\
\hline & & & $\%$ TSP & $\mu \mathrm{g} / \mathrm{g} F L T$ & & \\
\hline \multirow[t]{9}{*}{$\begin{array}{l}\text { Foot-and-mouth } \\
\text { disease virus }\end{array}$} & \multirow[t]{2}{*}{ VP1 } & $\begin{array}{l}\text { Chenopodium quinoa, Nicotiana } \\
\text { benthamiana/Bamboo mosaic virus }\end{array}$ & & $200-500 *$ & Swine & Yang et al. (2007) \\
\hline & & $\begin{array}{l}\text { Chenopodium amaranticolor, } \\
\text { N. benthamiana/Tobacco } \\
\text { necrosis virus-A }\end{array}$ & & $30-330 *$ & Mice & Zhang et al. (2010) \\
\hline & VP1 & $\begin{array}{l}\text { Stylosanthes guianensis/transgenic } \\
\text { plants }\end{array}$ & \multicolumn{2}{|l|}{$0.1-0.5$} & Mice & Wang et al. (2008) \\
\hline & $\mathrm{P} 1$ & $\begin{array}{l}\text { Nipponbare (Japonica rice)/ } \\
\text { transgenic plants }\end{array}$ & \multicolumn{2}{|l|}{$0.06-0.13$} & Mice & Wang et al. (2012) \\
\hline & VP1 & Crotalaria juncea/transgenic plants & \multicolumn{2}{|l|}{$0.0001-0.0012$} & Guinea pigs & Rao et al. (2012) \\
\hline & P1-2A3C & Tomato/transgenic plants & $n / r$ & \multirow[t]{4}{*}{$n / r$} & Guinea pigs & Pan et al., 2008; \\
\hline & VP1 & Nicotiana tabacum/transplastomic plants & $2-3$ & & n/a & Li et al. (2006) \\
\hline & VP1 & N. tabacum/transplantomic plants & 51 & & Mice & Lentz et al. (2010) \\
\hline & VP1, VP4, 2C, 3D & N. benthamiana/transient expression & $0.7-1$ & & Guinea pigs & Andrianova et al. (2011) \\
\hline \multirow[t]{5}{*}{ Rotavirus } & VP2, VP6, VP7 & N. benthamiana/transgenic plants & $\leq 0.15$ & & Mice & Yang et al. (2011) \\
\hline & VP2, VP6 & Tomato/transgenic plants & 1 & & Mice & Saldaña et al. (2006) \\
\hline & VP6 & C. amaranticolor/transient expression & 0.25 & & Mice & Zhou et al. (2010) \\
\hline & VP6 & Medicago sativa/transgenic plants & $0.06-0.28$ & & Mice & Dong et al. (2005) \\
\hline & VP8 & N. benthamiana/transplastomic plants & & 600 & Mice & Lentz et al. (2011) \\
\hline Bovine Papillomavirus & $\mathrm{L} 1$ & N. benthamiana/transient expression & & 183 & Rabbit & Love et al. (2012) \\
\hline Bluetongue virus & VP2, VP3, VP5, VP7 & N. benthamiana/transient expression & & $>200$ & Sheep & $\begin{array}{l}\text { Thuenemann } \\
\text { et al. (2013) }\end{array}$ \\
\hline Bovine viral & E2 & N. tabacum/transient expression & & 20 & Guinea pigs & Nelson et al. (2012) \\
\hline Diarrhoea virus & E2 & M. sativa/transgenic plants & & 1 & $\begin{array}{l}\text { Guinea } \\
\text { pigs/cattle }\end{array}$ & $\begin{array}{l}\text { Aguirreburualde } \\
\text { et al. (2013) }\end{array}$ \\
\hline
\end{tabular}

FLT, Fresh leaf tissue; TSP, Total soluble protein; n/r, not reported; n/a, not assayed.

* Yield of purified chimeric virus is provided.

with the virus of both serotypes. Guinea pigs immunized with the conventional inactivated vaccine were fully protected against challenge, and the authors suggest that this could be due to the presence of conformational epitopes of the capsid proteins, whereas the other groups carry only two sequential epitopes which may not be sufficient for protecting animals against FMDV by needle challenge.

It has been well documented that conformational B-cell epitopes form the majority of strong antibody binding epitopes on most proteins (Van Regenmortel, 1989). Therefore, virus-like particles (VLPs) - displaying antigenic epitopes in the correct conformation and in a highly repetitive manner-are able to induce strong humoral and cellular immune responses, becoming potent immunogens (Grgacic and Anderson, 2006; Kushnir et al., 2012; Roy and Noad, 2008). Over the last three decades, VLPS have been increasingly recognized as safe, effective vaccine candidates for viral diseases (Liu et al., 2012; Noad and Roy, 2003; Zeltins, 2013), and many attempts have been made to produce FMD VLPs using different expression systems (Mignaqui et al., 2013; Moraes et al., 2011; Porta et al., 2013a,b). The production of recombinant FMD VLPs requires the co-expression of the capsid precursor P12A and the protease $3 \mathrm{C}$. This viral protease processes the $\mathrm{P} 12 \mathrm{~A}$ precursor to generate structural proteins (VPO, VP3 and VP1), which then self-assemble to form the viral capsid (Belsham, 1993). The first approach to develop plant-based production of FMDV VLPS was carried out by our group, using stable transformation of alfalfa plants containing the genes encoding the polyprotein P12A and the protease $3 \mathrm{C}$ of
FMDV serotype 01Campos (Dus Santos et al., 2005). Preliminary results obtained by electronic microscopy showed spherical structures of $30 \mathrm{~nm}$ in diameter in the transgenic plant transfected with P1-3C that were absent in a plant carrying a nonrelated gene. These structures were able to evoke a strong antibody response in parenterally immunized mice, as well as complete protection against experimental challenge with virulent virus. Similarly, transgenic tomato plants expressing P12A and protease $3 \mathrm{C}$ were produced. Although an electron microscopy analysis to conclusively determine whether capsid proteins assemble into VLPs was not performed, guinea pigs immunized with foliar extracts from P12A-3C-transgenic tomato plants developed a virus-specific antibody response and were protected against FMDV challenge (Pan et al., 2008).

\section{Rotavirus}

Group A rotavirus (RV) is the major leading cause of diarrhoea in mammalian species worldwide (Saif and Fernandez, 1996). In calves, it is responsible for important economic losses due to increases in morbidity, mortality, treatment costs and reductions in growth rates (Dhama et al., 2009). Although the clinical signs are of short duration, viral shedding persists for up to 3 weeks after infection, often leading to a seasonal permanent outbreak of diarrhoea in young calves once the infection has been declared in a herd. It has been well documented that effective vaccination can reduce morbidity and mortality in dairy and beef calves (Kollaritsch et al., 2015). Several strategies have been used to 
achieve promising results in the development of vaccines, including different plant species, single proteins, VLPs, antibodies and diverse methodologies (nuclear and plastid transformation, viral vectors) for the expression of rotavirus antigens (see Table 1)

Rotavirus VP6 protein has been successfully expressed in plants. Codon-optimized VP6 gene was inserted into the alfalfa genome using Agrobacterium-mediated transformation. Expression levels were $0.06 \%-0.28 \%$ of the TSP. Immunized mice showed high titres of IgG and mucosal IgA against VP6. Antibodies were efficiently transferred onto pups which developed less severe diarrhoea after challenge with RV (Dong et al., 2005). The authors suggested that the induction of significant mucosal immune response could be due to the bio-encapsulation of VP6 antigen in transgenic alfalfa plants. Delivery of antigens by the oral route can potentially elicit production of secretory IgA, which could greatly reduce infection and morbidity.

VP6 protein was also expressed in Chenopodium amaranticolor using a recombinant Beet black scorch virus (BBSV) which was engineered by substituting the viral coat protein $(C P)$ by a codonoptimized VP6 gene. Wild-type BBSV can infect sugar beet under natural conditions. However, infection with recombinant virus in the fields is limited to human intervention as CP-deleted BBSV is incapacitated from spreading amongst plants. In this work, recombinant VP6 was efficiently expressed in plant leaves and could induce an effective immune response in adult female mice after being administered orally. This response was evident in the humoral (IgG) immune system as well as at the local sites of antigen exposure (IgA). Moreover, $60 \%$ of suckling mice born to immunized dams were protected against challenge (Zhou et al., 2010)

Transplastomic tobacco plants represent an interesting platform for the production of recombinant antigens in molecular farming. In our laboratory, bovine RV VP8 protein was produced in tobacco chloroplasts. This protein accumulated to about $600 \mu \mathrm{g} / \mathrm{g}$ of fresh leaf tissue and $250 \mu \mathrm{g} / \mathrm{g}$ of fresh tissue could be recovered in a soluble fraction. It is important to note that the VP8 protein remained as a very stable protein with almost no additional proteolysis in senescent leaves. We also found that the insoluble fraction containing VP8 was devoid of nicotine. Mice immunized with two doses of VP8 produced in tobacco chloroplasts developed high antibody titres that neutralized infection in vitro (Lentz et al., 2011). Interestingly, these results were in accordance with those obtained in our group in which VP8 was expressed in bacteria (Bellido et al., 2009), showing that transplastomic plants constitute an effective alternative expression system

Rotavirus-like particles (RLPs) have the potential to be highly immunogenic and safe vaccine candidates against RV infection. Single-layered RLPs composed of rotavirus inner capsid protein VP2, double-layered RLPs composed of inner capsid proteins VP2/ 6 and triple-layered RLPs composed of inner and outer capsid proteins VP2/6/7 or VP2/6/7/4 have previously been produced successfully in baculovirus vector expression systems and extensively evaluated for the development of rotavirus subunit vaccines (Crawford et al., 1994; Fernandez et al., 1998; Jiang et al., 1998; Labbé et al., 1991; Marashi et al., 2014).

Saldaña et al. (2006) reported the successful expression of rotavirus capsid proteins VP2 and VP6 in fruits of transgenic tomato plants. The content of viral protein in tomatoes was $1 \%$ of TSP. The plant-expressed VP6 not only retained the ability to form trimmers but could also assemble around a VP2 core to form double-shelled RLPs. However, only a small proportion of VP2/
VP6 assembled into VLPs. Immunogenicity was evaluated in adult mice that were intraperitoneally inoculated with a protein extract from transgenic tomatoes. Anti-RV antibodies were detected in serum, but it was not possible to determine whether they were raised against VLPS or free RV proteins.

Another study described the co-expression of VP2, VP6 and VP7 of RV group $A$ in transgenic tobacco plants. Although expression levels were low, plant-derived VP2, VP6 and VP7 proteins self-assembled into $2 / 6$ or 2/6/7 VLPs. The TSP containing these VLPs was able to induce serum IgG and faecal IgA in mice immunized with cholera toxin as an adjuvant, with titres as high as those induced by an attenuated RV vaccine (Yang et al., 2011). VLP production should be optimized to become a vaccine candidate for the prevention of bovine rotavirus infection affordable for veterinary purposes.

\section{Other viral diseases in cattle}

Subunit vaccines and VLPS of diverse complexity based on capsid proteins from other animal viruses have also been produced in plants with varying yields (reviewed in Table 1).

Bovine papillomavirus (BPV) is a DNA oncogenic virus inducing hyperplastic benign lesions of both cutaneous and mucosal epithelia in cattle. These benign lesions generally regress but may also occasionally persist, leading to a high risk of evolving into cancer, particularly in the presence of environmental carcinogenic cofactors (Borzacchiello and Roperto, 2008). As the major coat protein of this virus, L1, can self-assemble into highly immunogenic VLPs, Love et al. (2012) transiently expressed codonoptimized BPV L1 gene in N. benthamiana plants using the pEAQ vector system (Sainsbury et al., 2009). In this report, the authors found that plant codon optimization of the BPV L1 gene substantially increased expression levels of the protein, with yields of $183 \mathrm{mg} / \mathrm{kg}$ of fresh weight leaf tissue of highly pure, structurally stable VLPs. Purified VLPs were capable of inducing a strong immune response in rabbits. In this work, protein yield exceeded the basic level required for economical production of a vaccine thus making BP VLPs excellent candidates for potential vaccines produced in plants.

Bluetongue virus is an insect-transmitted viral disease that affects wild and domestic ruminant species. Cattle are considered to be the reservoir host from which virus may be transmitted to susceptible animals by the BTV vector, Culicoides sp. midges.

Bluetongue virus infection in cattle is typically asymptomatic. Viremia is often prolonged thus making bovines an important source of infection from which virus is transmitted to haematophagous insects of the genus Culicoides. A variety of vaccines have been developed to prevent BTV infection of ruminants, including inactivated and attenuated virus vaccines, VLPs produced from recombinant baculoviruses and recombinant virus vector vaccines (Calvo-Pinilla et al., 2014). Therefore, any attempt to control bluetongue disease necessitates completely safe and potent vaccines affordable and available in sufficient quantities. Transient expression in plants represents an interesting strategy to produce the multilayered structure of BTV as it requires the simultaneous expression of four proteins (VP2, VP3, VP5 and VP7) and the correct assembly at a stoichiometric ratio. Attempts of transient expression of BTV VLPs in plants have been difficult owing to low yields. To solve this problem, the PlaProVa group obtained $N$. benthamiana codon-optimized genes expressing VP2, VP3, VP5 and VP7 proteins from the Netherlands NET2006/04 strain of BTV-8. Thuenemann et al. (2013) described 
the efficient production and assembly of BTV VLPS, expressing different amounts of VP2, VP3, VP5 and VP7 using the cowpea mosaic virus-based HyperTrans (CPMV-HT) and pEAQ plant transient expression vector system. Expression of more than one protein by the same vector was used as a strategy to solve the stoichiometric ratio, to obtain VLPs instead of core-like particles (CLPs). Total BTV-8 protein yield was $>200 \mathrm{mg}$ per $\mathrm{kg}$ biomass, and the final yield of gradient-purified VLPs was about $70 \mathrm{mg}$ per $\mathrm{kg}$. Immunogenicity of recombinant VLPs was assessed in two sheep, which were subcutaneously injected with three doses of $20 \mu \mathrm{g}$ of plant-made VLPs. Serum samples from both animals were positive for BTV antibodies and reacted against the four structural proteins as measured by ELISA and Western blot, respectively. Furthermore, challenge experiments in sheep demonstrated that plant-produced VLPs conferred an identical protective profile as that of the live attenuated BTV-8 vaccine. This work clearly showed the feasibility of using plants as a platform for the production of veterinary vaccines.

Bovine viral diarrhoea (BVD) infection, caused by a Pestivirus of the Flaviviridae family, is an important cause of morbidity in cattle and thus, of great economic losses worldwide. It is associated with several consequences, such as fertility problems, immunosuppression, diarrhoea, thrombocytopenia and, frequently, unapparent courses (Baker, 1995). Transplacental infection can lead to abortion, stillbirth, malformation or persistent infection of the calves.

Performance of commercially available inactivated vaccines is a controversial issue due to the diversity of circulating strains and the absence of experimental evidence of protection levels during different outcomes of the infection (Bolin, 1995). Therefore, the introduction of more efficacious vaccines is required by veterinarians and farmers.

The E2 glycoprotein has been used in various studies for the production of recombinant vaccines for the prevention of the disease caused by BVDV. None of the eukaryotic expression systems currently available allows the scale-up of production of recombinant glycoprotein at an accessible cost for veterinary industries.

A truncated version of E2 glycoprotein (tE2) of BVDV was expressed in tobacco plants. The construction was optimized by adding a signal peptide which directed the protein into the plant secretory pathway, the Kozak consensus sequence and the KDEL retention signal. Recombinant protein accumulated up to $20 \mu \mathrm{g}$ of tE2 per gram of fresh leaves. Immunization of guinea pigs with $20 \mu \mathrm{g}$ of tE2 induced neutralizing antibodies comparable to those induced by a whole virus vaccine (Nelson et al., 2012). We also developed transgenic alfalfa plants expressing tE2 from BVDV fused to a single-chain antibody which targets to antigen presenting cells (APCH-tE2). The concentration of recombinant protein obtained was $1 \mu \mathrm{g} / \mathrm{g}$ of fresh leaf tissue. The aqueous two-phase partitioning system (ATPS) was then used for concentration and partial purification of $\mathrm{APCH}$-tE2 from the plant extract. The expression of APCH-tE2 protein was quantified in all the plants generated, to assess the stability of the expression amongst the plants obtained by vegetative propagation. We demonstrated that APCH-tE2 was expressed stably and the accumulation of the antigen was similar in all the clones evaluated. Moreover, the expression levels remained practically unchanged when monitored during a 12-month experimental period. The immunogenicity of APCH-tE2 was evaluated in a guinea pig model. High neutralizing antibody titres were induced by the recombinant vaccine. In addition, the experimental vaccine was evaluated in cattle which were inoculated with two doses of $3 \mu \mathrm{g}$ of APCH-tE2. The immunogen evoked a strong neutralizing antibody response. More important, when animals were challenged with virulent BVDV, they showed complete virological protection. To our knowledge, this is the first work where vaccine efficacy is evaluated in the natural host not only measuring the antibody response but also assessing protection against infection and disease (Aguirreburualde et al., 2013).

\section{Discussion}

As with every new platform, it took time for molecular farming to reach the market, yet now the first plant-made products are becoming available, in areas such as (i) Enzyme Manufacture: Sigma-Aldrich, a US chemical company, has been marketing the biopharmaceutical products trypsin, avidin and beta-glucuronidase (GUS) processed from transgenic maize. Prodigene Corporation and Sigma-Aldrich (St. Louis, MO) are marketing aprotinin (Aprolizean) from maize and from a transgenic tobacco (Hood et al., 1997); (ii) Veterinary vaccines: Dow AgroSciences successfully registered the first plant-based vaccine for Newcastle disease virus in poultry in the United States in 2006. Recombinant viral HN protein was generated in plant cell lines via Agrobacterium transformation and could successfully protect chickens from viral challenge (G. A. Cardineau, H. S. Mason, J. Van Eck, D. D. Kirk, and A. M. Walmsley, 2004, PCT patent application 60/ 467,998, WO 2004/098533). This process was a proof-ofconcept exercise designed to test regulatory feasibility, but the product is not on the market (Meeusen et al., 2007); (iii) Antibody production: the Cuban company Heber Biotec produced the first plant-derived antibody used in the immunopurification of the recombinant hepatitis B antigen (HBsAg) for vaccine purposes (Valdés et al., 2003); and (iv) Therapeutic proteins for human use: the Israeli company Protalix has developed a method to produce a carrot cell-expressed form of the glucocerebrosidase enzyme, traded as ELELYSOTM (taliglucerase alfa), which was approved by the FDA in 2012 being the first FDA-approved plant cell-based recombinant therapeutic protein (http://www. protalix.com/products/elelyso-taliglucerase-alfa.asp).

Currently, $100 \%$ of commercially available bovine viral vaccines are produced with inactivated or attenuated virus. This clearly shows that until now, none of the subunit recombinant bovine viral vaccine has proved to be cost-efficient. The eventual approval and commercialization of recombinant bovine vaccines may largely depend on the profitability of vaccine production.

An ideal veterinary vaccine would preferably protect against multiple pathogens (multicomponent), be produced with ease and consistency according to current good manufacturing practices, be prepared in a formulation that retains potency for at least 1 year cold chain-free (or at most $4{ }^{\circ} \mathrm{C}$ ), be safe and free of side effects, induce an early onset of immunity, provide longterm protection against both disease and infection, allow serological discrimination between vaccination and infection, and be cheap enough to provide a cost-benefit advantage.

Plant-made veterinary vaccines technology has the potential to fulfil many —if not all_of these requirements, which should be regarded as challenges to be addressed in the not too distant future. The evidence is quickly mounting for the potential and feasibility of this technology. Plant biomass generation does not require prohibitive capital investment for building fermentation facilities, and there is no need to construct duplicate facilities for scaled up operation (Chen, 2008). Upstream processing in plant- 
based systems can be operated and scaled up in a flexible and cost-efficient manner that cannot be easily matched by fermentation-based technologies currently used for vaccine production (Chen et al., 2014; Tusé et al., 2014).

Although plants appear as a very promising platform technology and the above examples represent significant achievements, there is still extensive work to be done before plant production systems can be established as universally accepted approaches for PMVV and therapeutic manufacturing.

Based on the results surveyed in this study, we believe that vaccines against BTV and BVDV are the two major candidates to reach the market. In the case of BTV, plant-produced VLPs are probably as effective as insect or mammalian cell-made VLPS and are probably far cheaper and safer to produce and apply than attenuated BTV vaccines. In the case of BVDV, the inactivated vaccine presents a limitation for its industrial production, as it is not easy to obtain enough BVDV viral antigen. Moreover, it was recently demonstrated that the new fatal disease named bovine neonatal pancytopenia (BNP) is associated with alloantibodies that cross-react with the bovine kidney cell line used for the vaccine production (Bastian et al., 2011). Both the production capacity of 400 doses per $\mathrm{kg}$ of biomass in alfalfa transgenic plants and the protection obtained with this APCH-tE2 protein subunit vaccine in the natural host (cattle) confirm the feasibility of producing reliable vaccines in plants as an attractive and inexpensive alternative to conventional fermentation systems for vaccine production. Therefore, it is expected that the development of PMVVs will gain momentum in the coming years.

\section{Acknowledgements}

We are thankful to the grant SA/13/12, from the Scientific and Technological Cooperation Program between the Ministry of Science, Technology and Productive Innovation in Argentina (MINCyT) and the Department of Science and Technology from South Africa (DST). We thank Dra. Ana L. Cippola from Dirección Nacional Asistente de Relaciones Institucionales, INTA. We also thank Maria Colaneri for revision of the manuscript.

\section{Conflicts of interest}

The authors declare that they have no conflict of interest.

\section{References}

Aguirreburualde, M.S.P., Gómez, M.C., Ostachuk, A., Wolman, F., Albanesi, G., Pecora, A., Odeon, A., Ardila, F., Escribano, J.M., Santos, M.J.D. and Wigdorovitz, A. (2013) Efficacy of a BVDV subunit vaccine produced in alfalfa transgenic plants. Vet. Immunol. Immunopathol. 151, 315-324.

Andrianova, E.P., Krementsugskaia, S.R., Lugovskaia, N.N., Mayorova, T.K., Borisov, V.V., Eldarov, M.A., Ravin, N.V., Folimonov, A.S. and Skryabin, K.G. (2011) Foot and mouth disease virus polyepitope protein produced in bacteria and plants induces protective immunity in guinea pigs. Biochemistry (Mosc). 76, 339-346

Baker, J.C. (1995) The clinical manifestations of bovine viral diarrhea infection. Vet. Clin. North Am. Food Anim. Pract. 11, 425-445.

Bastian, M., Holsteg, M., Hanke-Robinson, H., Duchow, K. and Cussler, K. (2011) Bovine Neonatal Pancytopenia: is this alloimmune syndrome caused by vaccine-induced alloreactive antibodies? Vaccine, 29, 5267-5275.

Bellido, D., Craig, P.O., Mozgovoj, M.V., Gonzalez, D.D., Wigdorovitz, A., Goldbaum, F.A. and Dus Santos, M.J. (2009) Brucella spp. lumazine synthase as a bovine rotavirus antigen delivery system. Vaccine, 27, 136-145.
Belsham, G. (1993) Distinctive features of foot-and-mouth disease virus, a member of the picornavirus family; aspects of virus protein synthesis, protein processing and structure. Prog. Biophys. Mol. Biol. 60, 241-260.

Bolin, S.R. (1995) Control of bovine viral diarrhea infection by use of vaccination. Vet. Clin. North Am. Food Anim. Pract. 11, 615-625.

Borzacchiello, G. and Roperto, F. (2008) Bovine papillomaviruses, papillomas and cancer in cattle. Vet. Res. 39, 1-19.

Brun, A., Bárcena, J., Blanco, E., Borrego, B., Dory, D., Escribano, J.M., Le GallReculé, G., Ortego, J. and Dixon, L.K. (2011) Current strategies for subunit and genetic viral veterinary vaccine development. Virus Res. 157, 1-12.

Calvo-Pinilla, E., Castillo-Olivares, J., Jabbar, T., Ortego, J., De la Poza, F. and Marín-López, A. (2014) Recombinant vaccines against bluetongue virus. Virus Res. 182, 78-86.

Chen, Q. (2008) Expression and purification of pharmaceutical proteins in plants. Biol. Eng. 1, 291-321.

Chen, Q., Santi, L. and Zhang, C. (2014) Plant-made biologics. Biomed Res. Int., 2014, 10-13.

Crawford, S.E., Labbé, M., Cohen, J., Burroughs, M.H., Zhou, Y.J. and Estes, M.K. (1994) Characterization of virus-like particles produced by the expression of rotavirus capsid proteins in insect cells. J. Virol. 68, 5945-5952.

Crisci, E., Bárcena, J. and Montoya, M. (2012) Virus-like particles: the new frontier of vaccines for animal viral infections. Vet. Immunol. Immunopathol. 148, 211-225

Dhama, K., Chauhan, R.S., Mahendran, M. and Malik, S.V.S. (2009) Rotavirus diarrhea in bovines and other domestic animals. Vet. Res. Commun. 33 $1-23$.

Doel, T.R. (2003) FMD vaccines. Virus Res. 91, 81-99.

Dong, J.L., Liang, B.G., Jin, Y.S., Zhang, W.J. and Wang, T. (2005) Oral immunization with pBsVP6-transgenic alfalfa protects mice against rotavirus infection. Virology, 339, 153-163.

Dus Santos, M.J., Carrillo, C., Ardila, F., Ríos, R.D., Franzone, P., Piccone, M.E., Wigdorovitz, A. and Borca, M.V. (2005) Development of transgenic alfalfa plants containing the foot and mouth disease virus structural polyprotein gene P1 and its utilization as an experimental immunogen. Vaccine, 23, 1838-1843.

Fernandez, F.M., Conner, M.E., Hodgins, D.C., Parwani, A.V., Nielsen, P.R. Crawford, S.E., Estes, M.K. and Saif, L.J. (1998) Passive immunity to bovine rotavirus in newborn calves fed colostrum supplements from cows immunized with recombinant SA11 rotavirus core-like particle (CLP) or virus-like particle (VLP) vaccines. Vaccine, 16, 507-516.

Grgacic, E.V.L. and Anderson, D.A. (2006) Virus-like particles: passport to immune recognition. Methods, 40, 60-65.

Habiela, M., Seago, J., Perez-Martin, E., Waters, R., Windsor, M., Salguero, F.J., Wood, J., Charleston, B. and Juleff, N. (2014) Laboratory animal models to study foot-and-mouth disease: a review with emphasis on natural and vaccine induced immunity. J. Gen. Virol. 95, 2329-2345

Hood, E.E., Witcher, D.R., Maddock, S., Meyer, T., Baszczynski, C., Bailey, M., Flynn, P., Register, J., Marshall, L., Bond, D., Kulisek, E., Kusnadi, A., Evangelista, R., Nikolov, Z., Wooge, C., Mehigh, R.J., Hernan, R., Kappel, W.K., Ritland, D., Li, C.P. and Howard, J.A. (1997) Commercial production of avidin from transgenic maize: characterization of transformant, production, processing, extraction and purification. Mol. Breed. 3, 291-306.

Jamal, S.M. and Belsham, G.J. (2013) Foot-and-mouth disease: past, present and future. Vet. Res. 44, 1-14.

Jiang, B., Barniak, V., Smith, R.P., Sharma, R., Corsaro, B., Hu, B. and Madore, H.P. (1998) Synthesis of rotavirus-like particles in insect cells: comparative and quantitative analysis. Biotechnol. Bioeng. 60, 369-374.

Knowles, N. and Samuel, A. (2003) Molecular epidemiology of FMDV. Virus Res. 91, 65-80.

Kollaritsch, H., Kundi, M., Giaquinto, C. and Paulke-Korinek, M. (2015) Rotavirus vaccines: a Story of Success. Clin. Microbiol. Infect. 21, 735-743. doi:10.1016/j.cmi.2015.01.027.

Kushnir, N., Streatfield, S.J. and Yusibov, V. (2012) Virus-like particles as a highly efficient vaccine platform: diversity of targets and production systems and advances in clinical development. Vaccine, 31, 58-83.

Labbé, M., Charpilienne, A., Crawford, S.E., Estes, M.K. and Cohen, J. (1991) Expression of rotavirus VP2 produces empty corelike particles. J. Virol. 65, 2946-2952. 
Lentz, E.M., Segretin, M.E., Morgenfeld, M.M., Wirth, S.A., Santos, M.J.D., Mozgovoj, M.V., Wigdorovitz, A. and Bravo-Almonacid, F.F. (2010) High expression level of a foot and mouth disease virus epitope in tobacco transplastomic plants. Planta, 231, 387-395.

Lentz, E.M., Mozgovoj, M.V., Bellido, D., Santos, M.J.D., Wigdorovitz, A. and Bravo-Almonacid, F.F. (2011) VP8* antigen produced in tobacco transplastomic plants confers protection against bovine rotavirus infection in a suckling mouse model. J. Biotechnol. 156, 100-107.

Li, Y., Sun, M., Liu, J., Yang, Z., Zhang, Z. and Shen, G. (2006) High expression of foot-and-mouth disease virus structural protein VP1 in tobacco chloroplasts. Plant Cell Rep. 25, 329-333.

Liu, F., Ge, S., Li, L., Wu, X., Liu, Z. and Wang, Z. (2012) Virus-like particles: potential veterinary vaccine immunogens. Res. Vet. Sci. 93, 553-559.

Love, A.J., Chapman, S.N., Matic, S., Noris, E., Lomonossoff, G.P. and Taliansky, M. (2012) In planta production of a candidate vaccine against bovine papillomavirus type 1. Planta, 236, 1305-1313

Marashi, S.M., Jalilvand, S., Mollaei-Kandelous, Y., Shahmahmoodi, S., Rezaei, F., Salimi, V., Nejati, A., Validi, M. and Shoja, Z. (2014) Intra-peritoneal and intra-rectal immunogenicity induced by rotavirus virus like particles $2 / 6 / 7$ in mice. Microb. Pathog. 67-68, 48-54.

Meeusen, E.N.T., Walker, J., Peters, A., Pastoret, P.P. and Jungersen, G. (2007) Current status of veterinary vaccines. Clin. Microbiol. Rev. 20, 489-510.

Mignaqui, A.C., Ruiz, V., Perret, S., St-Laurent, G., Singh Chahal, P., Transfiguracion, J., Sammarruco, A., Gnazzo, V., Durocher, Y. and Wigdorovitz, A. (2013) Transient gene expression in serum-free suspensiongrowing mammalian cells for the production of foot-and-mouth disease virus empty capsids. PLOS ONE, 8, e72800.

Moraes, M.P., Segundo, F.D.-S., Dias, C.C., Pena, L. and Grubman, M.J. (2011) Increased efficacy of an adenovirus-vectored foot-and-mouth disease capsid subunit vaccine expressing nonstructural protein $2 \mathrm{~B}$ is associated with a specific T cell response. Vaccine, 29, 9431-9440.

Nelson, G., Marconi, P., Periolo, O., La Torre, J. and Alvarez, M.A. (2012) Immunocompetent truncated E2 glycoprotein of bovine viral diarrhea virus (BVDV) expressed in Nicotiana tabacum plants: a candidate antigen for new generation of veterinary vaccines. Vaccine, 30, 4499-4504.

Noad, R. and Roy, P. (2003) Virus-like particles as immunogens. Trends Microbiol. 11, 438-444

Obembe, O.O., Popoola, J.O., Leelavathi, S. and Reddy, S.V. (2011) Advances in plant molecular farming. Biotechnol. Adv. 29, 210-222.

Pan, L., Zhang, Y., Wang, Y., Wang, B., Wang, W., Fang, Y., Jiang, S., Lv, J., Wang, W., Sun, Y. and Xie, Q. (2008) Foliar extracts from transgenic tomato plants expressing the structural polyprotein, P1-2A, and protease, 3C, from foot-and-mouth disease virus elicit a protective response in guinea pigs. Vet. Immunol. Immunopathol. 121, 83-90.

Porta, C., Kotecha, A., Burman, A., Jackson, T., Ren, J., Loureiro, S., Jones, I.M., Fry, E.E., Stuart, D.I. and Charleston, B. (2013a) Rational engineering of recombinant picornavirus capsids to produce safe, protective vaccine antigen. PLoS Pathog. 9, e1003255. doi:10.1371/journal.ppat.1003255.

Porta, C., Xu, X., Loureiro, S., Paramasivam, S., Ren, J., Al-Khalil, T., Burman, A., Jackson, T., Belsham, G.J., Curry, S., Lomonossoff, G.P., Parida, S., Paton, D., Li, Y., Wilsden, G., Ferris, N., Owens, R., Kotecha, A., Fry, E., Stuart, D.I., Charleston, B. and Jones, I.M. (2013b) Efficient production of foot-andmouth disease virus empty capsids in insect cells following down regulation of $3 C$ protease activity. J. Virol. Methods, 187, 406-412.

Rao, J.P., Agrawal, P., Mohammad, R., Rao, S.K., Reddy, G.R., Dechamma, H.J. and Suryanarayana, V.V.S. (2012) Expression of VP1 protein of serotype A and $\mathrm{O}$ of foot-and-mouth disease virus in transgenic sunnhemp plants and its immunogenicity for guinea pigs. Acta Virol. 56, 91-99.

Rodriguez, L. and Grubman, M. (2009) Foot and mouth disease virus vaccines. Vaccine, 27, D90-D94.
Roy, P. and Noad, R. (2008) Virus-like particles as a vaccine delivery system. Myths and facts. Hum. Vaccin. 4, 5-8.

Rybicki, E.P. (2014) Plant-based vaccines against viruses. Virol. J. 11, 1-20, doi:10.1186/s12985-014-0205-0.

Saif, L.J. and Fernandez, F.M. (1996) Group A rotavirus veterinary vaccines. J. Infect. Dis. 174(Suppl), S98-S106.

Sainsbury, F., Thuenemann, E.C. and Lomonossoff, G.P. (2009) pEAQ: versatile expression vectors for easy and quick transient expression of heterologous proteins in plants. Plant Biotechnol. J. 7, 682-693.

Saldaña, S., Esquivel Guadarrama, F., Olivera Flores, T.D.J., Arias, N., López, S., Arias, C., Ruiz-Medrano, R., Mason, H., Mor, T., Richter, L., Arntzen, C.J. and Gómez Lim, M.A. (2006) Production of rotavirus-like particles in tomato (Lycopersicon esculentum L.) fruit by expression of capsid proteins VP2 and VP6 and immunological studies. Viral Immunol. 19, 42-53.

Sharma, A.K. and Sharma, M.K. (2009) Plants as bioreactors: recent developments and emerging opportunities. Biotechnol. Adv. 27, 811-832.

Thuenemann, E.C., Meyers, A.E., Verwey, J., Rybicki, E.P. and Lomonossoff, G.P. (2013) A method for rapid production of heteromultimeric protein complexes in plants: assembly of protective bluetongue virus-like particles. Plant Biotechnol. J. 11, 839-846.

Tusé, D., Tu, T. and McDonald, K.A. (2014) Manufacturing economics of plantmade biologics: case studies in therapeutic and industrial enzymes. Biomed Res. Int. 2014, 1-16.

Valdés, R., Reyes, B., Alvarez, T., García, J., Montero, J.A., Figueroa, A., Gómez, L., Padilla, S., Geada, D., Abrahantes, M.C., Dorta, L., Fernández, D., Mendoza, O., Ramirez, N., Rodriguez, M., Pujol, M., Borroto, C. and Brito, J. (2003) Hepatitis B surface antigen immunopurification using a plant-derived specific antibody produced in large scale. Biochem. Biophys. Res. Commun. 310, 742-747.

Van Regenmortel, M.H. (1989) The concept and operational definition of protein epitopes. Philos. Trans. R. Soc. Lond. B Biol. Sci. 323, 451-466.

Wang, D.M., Zhu, J.B., Peng, M. and Zhou, P. (2008) Induction of a protective antibody response to FMDV in mice following oral immunization with transgenic Stylosanthes spp. as a feedstuff additive. Transgenic Res. 17, 1163-1170.

Wang, Y., Shen, Q., Jiang, Y., Song, Y., Fang, L., Xiao, S. and Chen, H. (2012) Immunogenicity of foot-and-mouth disease virus structural polyprotein P1 expressed in transgenic rice. J. Virol. Methods, 181, 12-17.

Xu, J., Dolan, M.C., Medrano, G., Cramer, C.L. and Weathers, P.J. (2012) Green factory: plants as bioproduction platforms for recombinant proteins. Biotechnol. Adv. 30, 1171-1184

Yang, C.-D., Liao, J.-T., Lai, C.-Y., Jong, M.-H., Liang, C.-M., Lin, Y.-L., Lin, N.S., Hsu, Y.-H. and Liang, S.-M. (2007) Induction of protective immunity in swine by recombinant bamboo mosaic virus expressing foot-and-mouth disease virus epitopes. BMC Biotechnol. 7, 62

Yang, Y., Li, X., Yang, H., Qian, Y., Zhang, Y., Fang, R. and Chen, X. (2011) Immunogenicity and virus-like particle formation of rotavirus capsid proteins produced in transgenic plants. Sci. China Life Sci. 54, 82-89.

Yusibov, V., Streatfield, S.J. and Kushnir, N. (2011) Clinical development of plant-produced recombinant pharmaceuticals: vaccines, antibodies and beyond. Hum. Vaccin. 7, 313-321.

Zeltins, A. (2013) Construction and characterization of virus-like particles: a review. Mol. Biotechnol. 53, 92-107.

Zhang, Y., Li, J., Pu, H., Jin, J., Zhang, X., Chen, M., Wang, B., Han, C., Yu, J. and Li, D. (2010) Development of Tobacco necrosis virus A as a vector for efficient and stable expression of FMDV VP1 peptides. Plant Biotechnol. J. 8, 506-523.

Zhou, B., Zhang, Y., Wang, X., Dong, J., Wang, B., Han, C., Yu, J. and Li, D. (2010) Oral administration of plant-based rotavirus VP6 induces antigen-specific lgAs, IgGs and passive protection in mice. Vaccine, 28, 6021-6027. 